\title{
An epidemiological analysis of maxillofacial fractures: a 10-year cross-sectional cohort retrospective study of 1007 patients
}

\author{
Mihai Juncar ${ }^{1}$, Paul Andrei Tent ${ }^{1 *}$, Raluca lulia Juncar ${ }^{1}$, Antonia Harangus ${ }^{2}$ and Rivis Mircea ${ }^{3}$
}

\begin{abstract}
Background: Epidemiological data is providing vital indicators for organizing the financial resources related to a particular type of trauma, estimating expenses and training of dental practioners and ambulatory medical staff for collaboration with a certain pattern of patients. Knowing the etiology and epidemiology of a certain pathology is significant for approaching its means of prevention.
\end{abstract}

Methods: A 10-year retrospective statistical analysis of 1007 patients with maxillofacial fractures treated in a University Clinic of Oral and Maxillofacial Surgery in Romania was performed. The data were extracted from patients' medical records. Statistical analysis was performed. A value of $p<0.05$ was considered statistically significant.

Results: The incidence of maxillofacial fractures was high among patients in the 20-29 age group (35.9\%). Male patients $(90.57 \%, M: F=9.6: 1)$, having a low level of education (46.60\%) and living in urban areas (53.50\%) were more affected. The main cause of maxillofacial fractures was interpersonal violence (59.37\%), both in the mandibular and midface topographic regions ( $p=0.001, p=0.002$ ). In urban areas, fractures caused by interpersonal violence and road traffic accidents were predominant, while in rural areas, most of the fractures were due to interpersonal violence, domestic accidents, work accidents and animal attacks ( $p=0.001)$.

Conclusions: Interpersonal violence is the main cause of maxillofacial fractures having epidemic proportions. Male patients aged 20-29 years with a low level of education represent the major risk category. Considering the wide area of interpersonal aggression, both the medical staff in the hospital and in the dental offices must be educated in order to collaborate with possible violent patients. Dentists must be prepared to work on a post-traumatic dento-periodontal field. Taking all measures to prevent inter-human aggression is imperative and will lead to a major decrease in maxillofacial fractures and an overall increase of oral health in a population.

Keywords: Maxillofacial fractures, Maxillofacial trauma, Etiology, Epidemiology, Head and neck fractures

\section{Background}

Facial trauma is continually increasing worldwide, being the most frequent type of pathology diagnosed and treated in oral and maxillofacial surgery services $[1,2]$. The severity of maxillofacial trauma varies depending

\footnotetext{
*Correspondence: tent_andrei@yahoo.com

1 Department of Oral and Maxillofacial Surgery, University of Oradea,

Romania, Str. Piața 1 Decembrie, no.10, 410073 Oradea, Romania

Full list of author information is available at the end of the article
}

on the type of etiology, the kinetic energy of the wounding agent and nevertheless on the dynamics between the wounding agent and the recipient $[3,4]$. Injuries can be present both isolated or as part of a polytrauma, coexisting with intracranial, cerebral, ocular, spinal, thoracic or abdominal lesions that can significantly increase the complexity and morbidity of the case $[5,6]$. Alteration of the facial features of an individual may have functional, psychological, social and, not least, professional 
consequences, difficult to reverse over time $[7,8]$. In this context, the management of maxillofacial fractures can be complex, involving a multidisciplinary approach and high costs [1-3].

Maxillofacial fractures have a direct impact on oral health, opening of the fracture site in the oral cavity may favor the appearance of infections or osteitis [1-4]. Also associated dento-periodontal trauma can range from simple coronary fractures to dental avulsions followed by edentations, that may imply a secondary complex oral rehabilitation treatment which involves high costs $[5,6]$. The implications of a mandibulo-maxilary fixation (MMF) treatment should not be neglected either. The MMF is accompanied by difficulties in maintaining proper oral hygiene and periodontal distress [7]. Therefore the prevention of maxillo-facial fractures will lead directly to an overall increase in the public oral health [1-7].

The causes of maxillofacial fractures and the category of affected patients differ significantly depending on the socioeconomic, cultural, religious, educational and demographic status $[9,10]$. Determining the etiological and epidemiological factors of a disease in a certain geographical area, provides extremely important data for implementing adequate prevention, diagnostic and treatment methods [7-10]. For this purpose, many studies have been conducted worldwide, but no consensus has yet been reached regarding the main etiology of maxillofacial fractures, because of great differences from one region to another and evolution in time [5-12]. In our geographical region, there are currently no studies related to the etiology of the entire facial skeleton fractures $[3,13]$. In this context, we consider this shortcoming a public health emergency.

The aim of this study is to determine the epidemiology and the main etiology of maxillofacial fractures, as well as to correlate them in order to identify the main categories of affected patients depending on traumatic etiology. The results of this research will be useful in implementing legislative norms for the prevention of maxillofacial fractures, increasing general oral health, as well as in training the medical staff and dentists for the adequate management of this pathology and collaboration with a certain type of patients.

\section{Methods}

This study was conducted in a tertiary center of oral and maxillo-facial surgery from Romania. The patients were selected retrospectively over a 10 -year period. We mention that the addressability of maxillofacial trauma in the host center of the study comes from a wide geographical area in Eastern Europe. All patients included in the study signed an informed consent at the time of their admission to the clinical service, by which they agreed to the use of their anonymized medical data for scientific research purposes. In the case of patients under the age of 18, the informed consent was signed by the parent or their legal guardian. The study was approved by the Ethics Committee of Oradea University (IRB No. 35698/19.02.2018) and was therefore performed in accordance with the ethical standards laid down in the 2008 Declaration of Helsinki and its later amendments.

The study inclusion criteria were the following: presence of at least one fracture line in the facial skeleton, an episode of acute trauma in the disease history, paraclinical examinations (radiographic or computed tomographic examination) confirming the clinical diagnosis of fracture and evidencing its location and characteristics, treatment of the fracture performed in the study host institution. We mention that because of the epidemiological nature of this study, the postoperative follow-up period of the patients did not represent an inclusion or exclusion criteria of the participants.

The criteria of exclusion from the study were: patient without any fracture lines in the facial skeleton, pathological bone fracture, absence of complementary imaging investigations, treatment performed in another service. All patients with incomplete data in the medical record sheets were excluded from this study.

The data were extracted from patients' medical records, and the following variables divided into subgroups were monitored: sex (male/female), age (divided into 10-year age groups), environment of origin (urban/rural), level of education (no education-patients not having completed the 1st grade of primary school, primary school-the highest education level completed, middle school-the highest education level completed, high school-the highest education level completed, university studiespatients having graduated from a faculty), traumatic etiology, location of fracture lines in the facial skeleton (mandible/midface/combined), location of fracture lines in the mandible (symphyseal/parasymphyseal/lateral/ angle/ramus/condylar process (head or intracapsular, subcondylar region)/coronoid process/alveolar process), location of fracture lines in the midface (Le Fort I/Le Fort II/Le Fort III/ zygomatic complex/nasal bones/alveolar margin/orbit/anterior maxillary sinus wall). We mention that in the subcondylar region category we included both patients with condylar neck and subcondylar fractures.

To prevent bias all observation sheets were checked twice by both the author who collected the data and a member of the statistical team.

The size of the study was due to the period of time in which the data were collected, namely 10 years.

The data extracted from the medical sheets of the patients were centralized electronically by the authors 
using Microsoft Excel Software. Initially, descriptive statistics of the collected data was performed with an accuracy of two decimal percentage. For performing the statistical analysis and the statistical correlations between variables, MedCalc Statistical Software version 19.2 (MedCalc Software bvba, Ostend, Belgium;53 https ://www.medcalc.org; 2020) was used. Thus, nominal information was expressed in the statistical analysis as percentage and frequency. Using the chi-square test, the frequencies of a nominal variable between the categories of another nominal variable were compared. For a result to be considered statistically significant a value of $p<0.05$ was necessary.

\section{Results}

1569 clinical sheets with maxillo-facial trauma were found in our hospital's archive in the 10 year chosen timeline for this study. 562 patients were excluded from this study as follows: 251 trauma patients had only facial contusions without any fracture line being identifiable, 121 patients had incomplete data regarding the environment of origin, 175 patients had incomplete data regarding the level of education and 15 patients did not report the cause of trauma. 1007 patients with a total number of 1661 fracture lines in the facial skeleton were included in this study.
The most affected age group was $20-29$ years $\mathrm{n}=360$ (35.90\%), followed by $30-39$ years $\mathrm{n}=182(18.30 \%)$, $10-19$ years $\mathrm{n}=165(16.40 \%), 40-49 \mathrm{n}=124(12.30 \%)$, $50-59 \mathrm{n}=92(9.10 \%), 60-69 \mathrm{n}=44(4.40 \%), 70-79 \mathrm{n}=28$ $(2.40 \%)$ and $0-9$ years $n=12(1.20 \%)$.

The majority of the patients were male, $\mathrm{n}=912$ $(90.60 \%)$, women representing a small proportion, $\mathrm{n}=95$ (9.40\%). The $\mathrm{M} / \mathrm{F}$ ratio $=9.6 / 1$.

Patients living in urban areas, $\mathrm{n}=539$ (53.50\%), were more affected than those living in rural areas, $n=456$ (46.50\%).

Patients with no education, $n=477$ (46.40\%), had the highest frequency of maxillofacial fractures, being followed by patients having middle school studies, $\mathrm{n}=218$ (22.00\%), high school studies, $\mathrm{n}=175$ (17.60\%), university studies, $\mathrm{n}=71(7.20 \%)$, and primary school studies $\mathrm{n}=66(6.70 \%)$.

The main traumatic etiology was interpersonal violence (IPV), $n=598$ (59.38\%), followed by falls, $n=162$ (16.02\%), road traffic accidents (RTA), $n=85$ (8.41\%), domestic accidents, $\mathrm{n}=59$ (5.84\%), animal attacks, $\mathrm{n}=56$ (5.54\%), sports injuries, $\mathrm{n}=36$ (3.56\%), and work accidents, $\mathrm{n}=15$ (1.48\%).

The type of traumatic etiology was correlated with patients' age group (Table 1) and sex (Table 2). Children under the age of 9 years and patients aged over 70 years more frequently suffered maxillofacial fractures from

Table 1 Distribution of the types of traumatic etiology depending on age

\begin{tabular}{|c|c|c|c|c|c|c|c|c|}
\hline & \multicolumn{7}{|c|}{ Etiology of trauma } & \multirow[t]{2}{*}{ Total } \\
\hline & IPV & RTA & Domestic accident & Sports injury & Work accident & Fall & Animal attack & \\
\hline \multicolumn{9}{|l|}{ Age } \\
\hline \multirow[t]{2}{*}{$0-9$} & 1 & 2 & 1 & 0 & 0 & 5 & 3 & 12 \\
\hline & $0.2 \%$ & $2.4 \%$ & $1.7 \%$ & $0.0 \%$ & $0.0 \%$ & $3.2 \%$ & $5.4 \%$ & $1.2 \%$ \\
\hline \multirow[t]{2}{*}{$10-19$} & 98 & 17 & 3 & 11 & 0 & 24 & 12 & 165 \\
\hline & $16.5 \%$ & $20.0 \%$ & $5.1 \%$ & $30.6 \%$ & $0.0 \%$ & $15.2 \%$ & $21.4 \%$ & $16.4 \%$ \\
\hline \multirow[t]{2}{*}{$20-29$} & 261 & 30 & 19 & 12 & 4 & 28 & 6 & 360 \\
\hline & $43.9 \%$ & $35.3 \%$ & $32.2 \%$ & $33.3 \%$ & $26.7 \%$ & $17.7 \%$ & $10.7 \%$ & $35.9 \%$ \\
\hline \multirow[t]{2}{*}{$30-39$} & 100 & 14 & 15 & 10 & 3 & 30 & 10 & 182 \\
\hline & $16.8 \%$ & $16.5 \%$ & $25.4 \%$ & $27.8 \%$ & $20.0 \%$ & $19.0 \%$ & $17.9 \%$ & $18.3 \%$ \\
\hline \multirow[t]{2}{*}{$40-49$} & 64 & 11 & 7 & 1 & 5 & 29 & 7 & 124 \\
\hline & $10.8 \%$ & $12.9 \%$ & $11.9 \%$ & $2.8 \%$ & $33.3 \%$ & $18.4 \%$ & $12.5 \%$ & $12.3 \%$ \\
\hline \multirow[t]{2}{*}{$50-59$} & 48 & 6 & 7 & 2 & 2 & 19 & 8 & 92 \\
\hline & $8.1 \%$ & $7.1 \%$ & $11.9 \%$ & $5.6 \%$ & $13.3 \%$ & $12.0 \%$ & $14.3 \%$ & $9.1 \%$ \\
\hline \multirow[t]{2}{*}{$60-69$} & 16 & 3 & 4 & 0 & 1 & 11 & 9 & 44 \\
\hline & $2.7 \%$ & $3.5 \%$ & $6.8 \%$ & $0.0 \%$ & $6.7 \%$ & $7.0 \%$ & $16.1 \%$ & $4.4 \%$ \\
\hline \multirow[t]{2}{*}{$>70$} & 6 & 2 & 3 & 0 & 0 & 16 & 1 & 28 \\
\hline & $1.0 \%$ & $2.4 \%$ & $5.1 \%$ & $0.0 \%$ & $0.0 \%$ & $7.6 \%$ & $1.8 \%$ & $2.4 \%$ \\
\hline \multirow[t]{2}{*}{ Total $P=0.004$} & 598 & 85 & 59 & 36 & 15 & 162 & 56 & 1007 \\
\hline & $100.0 \%$ & $100.0 \%$ & $100.0 \%$ & $100.0 \%$ & $100.0 \%$ & $100.0 \%$ & $100.0 \%$ & $100.0 \%$ \\
\hline
\end{tabular}


Table 2 Distribution of the types of traumatic etiology depending on sex

\begin{tabular}{|c|c|c|c|c|c|c|c|c|}
\hline & \multicolumn{7}{|c|}{ Etiology of trauma } & \multirow[t]{2}{*}{ Total } \\
\hline & IPV & RTA & Domestic accident & Sports injury & Work accident & Fall & Animal attack & \\
\hline \multicolumn{9}{|l|}{ Sex } \\
\hline \multirow[t]{2}{*}{$\mathrm{F}$} & 35 & 25 & 2 & 0 & 1 & 25 & 7 & 95 \\
\hline & $5.9 \%$ & $29.4 \%$ & $3.4 \%$ & $0.0 \%$ & $6.7 \%$ & $15.8 \%$ & $12.5 \%$ & $9.4 \%$ \\
\hline \multirow[t]{2}{*}{ M } & 559 & 60 & 57 & 36 & 14 & 137 & 49 & 912 \\
\hline & $94.1 \%$ & $70.6 \%$ & $96.6 \%$ & $100.0 \%$ & $93.3 \%$ & $84.2 \%$ & $87.5 \%$ & $90.6 \%$ \\
\hline \multirow[t]{2}{*}{ Total $P=0.003$} & 598 & 85 & 59 & 36 & 15 & 162 & 56 & 1007 \\
\hline & $100.0 \%$ & $100.0 \%$ & $100.0 \%$ & $100.0 \%$ & $100.0 \%$ & $100.0 \%$ & $100.0 \%$ & $100.0 \%$ \\
\hline
\end{tabular}

IPV interpersonal violence, RTA road traffic accident

falling, while patients aged between 10 and 69 years had more fractures caused by interpersonal violence. This result was statistically significant $(p=0.004)$. The incidence of men with maxillofacial fractures was high in all categories of traumatic etiology, the result being statistically significant $(p=0.003)$.

The type of traumatic etiology was correlated with patients' level of education and environment of origin (Table 3). In urban areas, maxillofacial fractures caused by aggression and road traffic accidents were predominant, while in rural areas, those caused by animal attacks and domestic accidents $(p=0.001)$. Regarding the level of education, interpersonal violence was the main etiology in all categories. These results were statistically significant $(p=0.005)$.

Of all patients, 629 (62.46\%) had strictly mandibular fractures with a total of 1099 fracture lines, 297 (29.49\%) had strictly midface fractures, and 81 (8.04\%) had concomitant mandibular and midface fractures. The most frequent fracture site in the mandible was the angle $28.84 \%(\mathrm{n}=317)$, followed body $24.29 \%(\mathrm{n}=276)$, subcondylar region $22.02 \%(\mathrm{n}=242)$, parasymphyseal $17.38 \%(\mathrm{n}=191)$, symphyseal $3.18 \%(\mathrm{n}=35)$, ramus $2.00 \%(\mathrm{n}=22)$, coronoid process $1.18 \%(\mathrm{n}=13)$ and

Table 3 Distribution of the types of traumatic etiology depending on the level of education and environment

\begin{tabular}{|c|c|c|c|c|c|c|c|c|}
\hline \multirow[t]{2}{*}{ Level of education } & \multicolumn{8}{|c|}{ Etiology of trauma } \\
\hline & IPV & RTA & Domestic accident & Sports injury & Work accident & Fall & Animal attack & Total \\
\hline \multirow[t]{2}{*}{ No education } & 276 & 36 & 27 & 10 & 9 & 85 & 34 & 477 \\
\hline & $45.2 \%$ & $41.7 \%$ & $44.8 \%$ & $25.7 \%$ & $60.0 \%$ & $52.6 \%$ & $60.0 \%$ & $46.4 \%$ \\
\hline \multirow[t]{2}{*}{ Primary school } & 32 & 4 & 0 & 1 & 1 & 15 & 13 & 66 \\
\hline & $5.1 \%$ & $4.8 \%$ & $0.0 \%$ & $2.9 \%$ & $6.7 \%$ & $9.7 \%$ & $23.6 \%$ & $6.7 \%$ \\
\hline \multirow[t]{2}{*}{ Middle school } & 135 & 14 & 21 & 7 & 3 & 31 & 7 & 218 \\
\hline & $23.1 \%$ & $16.7 \%$ & $36.2 \%$ & $20.0 \%$ & $20.0 \%$ & $20.1 \%$ & $12.7 \%$ & $22.0 \%$ \\
\hline \multirow[t]{2}{*}{ High school } & 114 & 21 & 8 & 9 & 1 & 20 & 2 & 175 \\
\hline & $19.3 \%$ & $25.0 \%$ & $13.8 \%$ & $25.7 \%$ & $6.7 \%$ & $13.0 \%$ & $3.6 \%$ & $17.6 \%$ \\
\hline \multirow[t]{2}{*}{ University studies } & 41 & 10 & 3 & 9 & 1 & 7 & 0 & 71 \\
\hline & $7.0 \%$ & $11.9 \%$ & $5.2 \%$ & $25.7 \%$ & $6.7 \%$ & $4.5 \%$ & $0.0 \%$ & $7.2 \%$ \\
\hline \multirow[t]{2}{*}{ Total $P=0.005$} & 598 & 85 & 59 & 36 & 15 & 158 & 56 & 1007 \\
\hline & $100.0 \%$ & $100.0 \%$ & $100.0 \%$ & $100.0 \%$ & $100.0 \%$ & $100.0 \%$ & $100.0 \%$ & $100.0 \%$ \\
\hline \multicolumn{9}{|l|}{ Environment } \\
\hline \multirow[t]{2}{*}{$\mathrm{R}$} & 263 & 35 & 33 & 9 & 9 & 72 & 47 & 468 \\
\hline & $43.8 \%$ & $41.2 \%$ & $55.9 \%$ & $25.0 \%$ & $60.0 \%$ & $45.6 \%$ & $83.9 \%$ & $46.5 \%$ \\
\hline \multirow[t]{2}{*}{ U } & 335 & 50 & 26 & 27 & 6 & 86 & 9 & 539 \\
\hline & $56.2 \%$ & $58.8 \%$ & $44.1 \%$ & $75.0 \%$ & $40.0 \%$ & $54.4 \%$ & $16.1 \%$ & $53.5 \%$ \\
\hline \multirow[t]{2}{*}{ Total $P=0.001$} & 598 & 85 & 59 & 36 & 15 & 158 & 56 & 1007 \\
\hline & $100.0 \%$ & $100.0 \%$ & $100.0 \%$ & $100.0 \%$ & $100.0 \%$ & $100.0 \%$ & $100.0 \%$ & $100.0 \%$ \\
\hline
\end{tabular}


alveolar process $1.09 \%(n=12)$. No intracapsular condylar fractures were identified. Mandibular fractures were most frequently caused by interpersonal violence $p=0.001$. Table 4 shows the distribution of the fracture lines location depending on etiology. Similarly to the situation of lower face fractures, interpersonal violence was the main cause of midface fractures. In Table 5, the distribution of the fracture lines depending on location and cause can be observed (Additional files 1,2).

\section{Discussion}

This study evidences a high incidence of maxillofacial fractures in the 20-29 age group, which is in accordance with the results reported by other authors $[2,4,9-20]$. This finding can be due to the fact that during this life decade, individuals are more socially, professionally and physically active, being more exposed to trauma [2-4]. Young people are more extroverted and participate in social events more often [12]. In these circumstances, consumption of alcohol or recreational drugs predisposes them to interpersonal conflicts which can lead to physical aggression [12, 21, 22]. For the same reasons, the patients belonging to this life decade are predisposed to road traffic accidents due to their lack of experience, breaking of traffic rules or high-speed driving [15-23]. Contrary to our findings, in other studies the incidence of maxillofacial fractures is predominant in the 30-39 age group [24-26]. This can be attributed to global population aging [17].

Maxillofacial fractures predominate among men, both in this study and in the literature [9-23]. Behaviorally, men are more predisposed to engage in interpersonal conflicts than women, therefore the risk to suffer a fracture caused by aggression being higher [27]. With respect to daily activities, men are more frequently involved in physical work, for example in construction works, being more predisposed to work accidents [23-27]. Extreme sports or contact sports are also predominantly practiced by men, who are at a higher risk for maxillofacial fractures caused by sports injuries [2-6]. However, in developed countries, where women are involved in society as much as men, the male/female ratio tends to decrease [28-30].

A higher incidence of maxillofacial fractures was found in urban areas in our study, which is in accordance with the results of other publications [27, 31-33]. The high

Table 4 Distribution of mandibular fractures depending on etiology

\begin{tabular}{|c|c|c|c|c|c|c|c|c|}
\hline & \multicolumn{7}{|c|}{ Etiology of trauma } & \multirow[t]{2}{*}{ Total } \\
\hline & IPV & RTA & Domestic accident & Sports injury & Work accident & Fall & Animal attack & \\
\hline \multicolumn{9}{|l|}{ Mandibular fractures } \\
\hline \multirow[t]{2}{*}{ Absent } & 140 & 37 & 30 & 20 & 6 & 49 & 19 & 301 \\
\hline & $23.6 \%$ & $43.5 \%$ & $50.8 \%$ & $55.6 \%$ & $40.0 \%$ & $31.0 \%$ & $33.9 \%$ & $29.9 \%$ \\
\hline \multirow[t]{2}{*}{ Symphyseal } & 3 & 3 & 0 & 0 & 1 & 1 & 0 & 8 \\
\hline & $0.5 \%$ & $3.5 \%$ & $0.0 \%$ & $0.0 \%$ & $6.7 \%$ & $0.6 \%$ & $0.0 \%$ & $0.8 \%$ \\
\hline \multirow[t]{2}{*}{ Parasymphyseal } & 18 & 3 & 4 & 0 & 0 & 7 & 2 & 34 \\
\hline & $3.0 \%$ & $3.5 \%$ & $6.8 \%$ & $0.0 \%$ & $0.0 \%$ & $4.4 \%$ & $3.6 \%$ & $3.4 \%$ \\
\hline \multirow[t]{2}{*}{ Body } & 37 & 7 & 2 & 2 & 2 & 15 & 6 & 71 \\
\hline & $6.1 \%$ & $8.2 \%$ & $3.4 \%$ & $5.6 \%$ & $13.3 \%$ & $9.5 \%$ & $10.7 \%$ & $7.1 \%$ \\
\hline \multirow[t]{2}{*}{ Angle } & 107 & 0 & 4 & 2 & 1 & 19 & 3 & 136 \\
\hline & $17.8 \%$ & $0.0 \%$ & $6.8 \%$ & $5.6 \%$ & $6.7 \%$ & $12.0 \%$ & $5.4 \%$ & $13.5 \%$ \\
\hline \multirow[t]{2}{*}{ Ramus } & 2 & 0 & 1 & 0 & 0 & 1 & 2 & 6 \\
\hline & $0.3 \%$ & $0.0 \%$ & $1.7 \%$ & $0.0 \%$ & $0.0 \%$ & $0.6 \%$ & $3.6 \%$ & $0.6 \%$ \\
\hline \multirow[t]{2}{*}{ Subcondylar region } & 39 & 4 & 3 & 3 & 0 & 16 & 4 & 69 \\
\hline & $6.6 \%$ & $4.7 \%$ & $5.1 \%$ & $8.3 \%$ & $0.0 \%$ & $10.1 \%$ & $7.1 \%$ & $6.9 \%$ \\
\hline \multirow[t]{2}{*}{ Coronoid process } & 0 & 2 & 1 & 1 & 0 & 1 & 0 & 5 \\
\hline & $0.0 \%$ & $2.4 \%$ & $1.7 \%$ & $2.8 \%$ & $0.0 \%$ & $0.6 \%$ & $0.0 \%$ & $0.5 \%$ \\
\hline \multirow[t]{2}{*}{ Alveolar process } & 3 & 1 & 0 & 1 & 0 & 1 & 2 & 8 \\
\hline & $0.5 \%$ & $1.2 \%$ & $0.0 \%$ & $2.8 \%$ & $0.0 \%$ & $0.6 \%$ & $3.6 \%$ & $0.8 \%$ \\
\hline \multirow[t]{2}{*}{ Multiple } & 249 & 28 & 14 & 7 & 5 & 48 & 18 & 369 \\
\hline & $41.6 \%$ & $32.9 \%$ & $23.7 \%$ & $19.4 \%$ & $33.3 \%$ & $30.4 \%$ & $32.1 \%$ & $36.6 \%$ \\
\hline \multirow[t]{2}{*}{ Total $P=0.001$} & 598 & 85 & 59 & 36 & 15 & 158 & 59 & 1007 \\
\hline & $100 \%$ & $100 \%$ & $100 \%$ & $100 \%$ & $100 \%$ & $100 \%$ & $100 \%$ & $100 \%$ \\
\hline
\end{tabular}


Table 5 Distribution of midface fractures depending on etiology

\begin{tabular}{|c|c|c|c|c|c|c|c|c|}
\hline & \multicolumn{7}{|c|}{ Etiology of trauma } & \multirow[t]{2}{*}{ Total } \\
\hline & IPV & RTA & Domestic accident & Sports injury & Work acc & Fall & Animal attack & \\
\hline \multicolumn{9}{|l|}{ Midface fractures } \\
\hline \multirow[t]{2}{*}{ Absent } & 428 & 25 & 27 & 15 & 7 & 95 & 29 & 626 \\
\hline & $71.5 \%$ & $29.4 \%$ & $45.8 \%$ & $41.7 \%$ & $46.7 \%$ & $60.1 \%$ & $51.8 \%$ & $62.2 \%$ \\
\hline \multirow[t]{2}{*}{ Le Fort I } & 0 & 0 & 1 & 0 & 0 & 2 & 1 & 4 \\
\hline & $0.0 \%$ & $0.0 \%$ & $1.7 \%$ & $0.0 \%$ & $0.0 \%$ & $1.3 \%$ & $1.8 \%$ & $0.4 \%$ \\
\hline \multirow[t]{2}{*}{ Le Fort II } & 5 & 1 & 0 & 0 & 1 & 2 & 0 & 9 \\
\hline & $0.8 \%$ & $1.2 \%$ & $0.0 \%$ & $0.0 \%$ & $6.7 \%$ & $1.3 \%$ & $0.0 \%$ & $0.9 \%$ \\
\hline \multirow[t]{2}{*}{ Le Fort III } & 1 & 1 & 2 & 0 & 1 & 0 & 0 & 5 \\
\hline & $0.2 \%$ & $1.2 \%$ & $3.4 \%$ & $0.0 \%$ & $6.7 \%$ & $0.0 \%$ & $0.0 \%$ & $0.5 \%$ \\
\hline \multirow[t]{2}{*}{ Zygomatic } & 88 & 19 & 10 & 11 & 2 & 29 & 13 & 172 \\
\hline & $14.6 \%$ & $22.4 \%$ & $16.9 \%$ & $30.6 \%$ & $13.3 \%$ & $18.4 \%$ & $23.2 \%$ & $17.1 \%$ \\
\hline \multirow[t]{2}{*}{ Nasal bones } & 30 & 6 & 4 & 7 & 0 & 10 & 0 & 57 \\
\hline & $5.1 \%$ & $7.1 \%$ & $6.8 \%$ & $19.4 \%$ & $0.0 \%$ & $6.3 \%$ & $0.0 \%$ & $5.7 \%$ \\
\hline \multirow[t]{2}{*}{ Alveolar process } & 9 & 6 & 4 & 1 & 0 & 4 & 3 & 27 \\
\hline & $1.5 \%$ & $7.1 \%$ & $6.8 \%$ & $2.8 \%$ & $0.0 \%$ & $2.5 \%$ & $5.4 \%$ & $2.7 \%$ \\
\hline \multirow[t]{2}{*}{ Orbit } & 0 & 1 & 2 & 1 & 0 & 1 & 0 & 5 \\
\hline & $0.0 \%$ & $1.2 \%$ & $3.4 \%$ & $2.8 \%$ & $0.0 \%$ & $0.6 \%$ & $0.0 \%$ & $0.5 \%$ \\
\hline \multirow[t]{2}{*}{ Anterior maxillary sinus wall } & 1 & 0 & 0 & 0 & 0 & 0 & 0 & 1 \\
\hline & $0.2 \%$ & $0.0 \%$ & $0.0 \%$ & $0.0 \%$ & $0.0 \%$ & $0.0 \%$ & $0.0 \%$ & $0.1 \%$ \\
\hline \multirow[t]{2}{*}{ Multiple } & 36 & 26 & 9 & 1 & 4 & 15 & 10 & 101 \\
\hline & $6.1 \%$ & $30.6 \%$ & $15.3 \%$ & $2.8 \%$ & $26.7 \%$ & $9.5 \%$ & $17.9 \%$ & $10.0 \%$ \\
\hline \multirow[t]{2}{*}{ Total $P=0.002$} & 598 & 85 & 59 & 36 & 15 & 158 & 56 & 1007 \\
\hline & $100 \%$ & $100 \%$ & $100 \%$ & $100 \%$ & $100 \%$ & $100 \%$ & $100 \%$ & $100 \%$ \\
\hline
\end{tabular}

IPV interpersonal violence, RTA road traffic accident

density of the population in the urban environment, the great discrepancies between social classes, the easy access to alcohol or narcotic substances are factors that contribute to increasing the risk of interpersonal conflicts [27, 31-33]. Also, the city infrastructure based on highways allowing high-speed circulation of vehicles, concomitantly with the multiplying number of vehicles, leads to an increase in the risk of road traffic accidents [27-33]. Contrary to our findings, other studies indicate a higher frequency of maxillofacial fractures in rural areas [34]. These discrepancies can be explained by the differences between the regions served by the institutions in which those studies were carried out [34]. In our study, an increased incidence of interpersonal violence in both environments was found. This result is uncommon and rarely found in the existing literature [2, 6]. Also our institution where the study took place serves many counties composed of both urban and rural regions. This fact can also explain our result.

In our study we found that most of the affected patients had a low level of education. This result is also reported by other authors $[17,35,36]$ A lower education level predisposes to unemployment, low social status, material deficiencies and implicitly, limited access to healthcare services [17]. All these factors can lead to frustration and depression which, supported by alcohol or drug consumption, can lead to conflicts and interpersonal violence $[22,23,35,36]$. These findings are upheld by other authors who certify the small number of traumas secondary to aggression in a population with a high education level $[23,36]$. Also, in the context of the absence of an intellectual qualification, people are forced to earn their living by practicing unqualified physical work [17]. The risk to suffer a maxillofacial fracture through a work accident is higher in this context compared to the intellectual work environment [17]. According to our and other authors' results, the increase in the education level of a population is a significant method for the prevention of maxillofacial fractures $[22,23,36]$. Although the highest incidence of fractures caused by interpersonal violence was found among patients without education, our study evidences the predominance of interpersonal violence as a main etiological factor in the other education level categories as well. This fact is rarely found in the literature and it must be considered an alarm signal in public health [22-27]. 
The most frequent mechanism of maxillofacial fractures was interpersonal violence, a result also found in studies conducted in other geographical areas such as Germany [37], Brazil [6, 33], USA [24, 31, 39], Italy [26, 38], Australia [7], Norway [2, 29] or Sweden [40]. The incidence of interpersonal violence has increased over the past decade in developed countries [29-39]. Recent European studies confirm a shift of the main etiological factor of maxillofacial fractures from road traffic accidents or sports injuries to interpersonal violence [2, 26, 40]. The cultural, social and educational mosaic in the cities of developed countries is an environment that constantly predisposes to interpersonal conflicts and implicitly, to maxillofacial fractures [26-39]. The interrelation between interpersonal violence and alcohol found in developed countries should not be overlooked either [37-40]. For example, in Arab countries where alcohol consumption is restricted or even forbidden by law, interpersonal violence has a low incidence [5, 41].

In contrast to our findings, in studies conducted in regions such as Nigeria [42], Uganda [20], India [17, 19, 27], Egypt [1], Saudi Arabia [5, 41], China [19], South Korea [15, 30], Malaysia [16, 43] or Iran [44], maxillofacial fractures caused by road traffic accidents are predominant. The high incidence of maxillofacial fractures through road traffic accidents in developing countries is due to many factors: poorly defined traffic rules, deliberately driving unapproved or uninspected vehicles and, not least, inadequate traffic lighting and marking of roads $[5,17-20,41-44]$. A high frequency of road traffic accidents is also reported in developed countries with an increased population density, where such accidents are caused by the carelessness and non-compliance of drivers with the traffic rules [19-30]. In our country, the welldefined traffic rules, as well as the high penalties for their infringement, have lately led to a considerable reduction in the number of maxillofacial fractures caused by road traffic accidents. In contrast to the above publications, other authors report falling as the main cause of maxillofacial fractures $[28,45-47]$. This can be due to effective prevention of interpersonal violence and traffic accidents in the geographical areas where the studies were conducted [47]. Global population aging should not be overlooked either, as the predisposition of elderly persons to facial trauma from falling is well known [5, 40-47]. This is also evidenced by our findings.

Maxillofacial fractures caused by work accidents, domestic accidents or animal attacks had a low incidence in this study, being predominant in rural areas. These findings are consistent with those reported in the literature [1-25].

The mandible was the most fractured bone in this study, in accordance with the literature data [1-25] This finding is not surprising given the prominence of the mandible in the lower face, being directly exposed to trauma [1-25]. Regarding the most frequent location of the fracture line in the mandible, authors' opinions diverge. According to our and other authors' findings, mandibular angle fractures are the most frequent [47, 49], while other authors report the highest frequency of subcondylar region fractures [23,50], or parasymphyseal mandibular fractures [52]. The location of the fracture line in the mandible varies depending on the type, texture, place of action, speed and kinetic energy of the wounding agent on the one hand, and on the position of the head and time of impact on the other hand [48-52]. This explains the discrepancies described in the literature related to this aspect [48-52].

In the midface, the most fractured bone was the zygomatic bone, which is supported by other authors [3-10, $17,20,27]$. The zygomatic bone is the lateral pillar of the midface, absorbing most of the traumatic forces in this region $[20,27]$. The fact that individuals tend to turn their head at the time of the impact in order to avoid frontal or ocular contact should also be considered [17-20,27]. All this makes the zygomatic complex more susceptible to fracture [20, 27]. Contrary to our findings, other authors indicate the highest incidence of nasal bone fractures $[42,53]$ or orbital fractures $[26,34,54]$. The sagittal prominence of the nasal bones in the face explains the high incidence of fractures at this level $[42,53]$. Biomechanically, the nasal bones have a decreased resistance to trauma $[42,53,54]$. The fact that in this study lateral orbital wall and orbital floor fractures were included as zygomatic complex fractures category, explains the small number of orbital fractures in our findings. In our study the majority of patients with multiple fracture lines in the midface caused by interpersonal violence is higher than those caused by RTAs. This is uncommon and rarely reported in the literature [1, 18, 24, 25]. Patients suffer multiple fracture lines in the midface usually secondary to RTAs due to the high kinetic energy developed, rather than human aggression $[1,18,24,25]$.

We believe that this study is providing vital information regarding the etiology and epidemiology of maxillo-facial fractures. This information can be used for managing the distribution of financial resources in healthcare services, preparing the doctors and nurses in order to relate to a certain type of the patients, and not least it can be used for implementing preventive measures regarding this particular pathology.

However there are several limitations that have to be taken into consideration regarding this study. A major limitation is that this study is a retrospective one. In these circumstances, the data taken from the observation sheets may be incomplete or erroneously recorded at 
the time of patient submission. A randomised controlled trial study should be done in the future to avoid these shortcomings. The possibility of people intentionally misreporting the cause of the trauma must also be considered. This occurs frequently in the case of inter-personal aggression, victims often indicate a different cause of trauma out of fear or to avoid certain legal implications.

\section{Conclusions}

Interpersonal violence represents the main etiology of maxillofacial fractures, having epidemic proportions in rural and urban areas. Male patients aged between 20 and 29 years with a low level of education represent the major risk category. The mandible is the most fractured bone of the face, followed by the zygomatic bone. Increasing the legal punishments in case of aggression, as well as the global increase of education in our population can lead to an overall decrease of the number of maxillofacial fractures. Measures for educating the medical and auxiliary staff to communicate with aggressive patients are imperative in order to facilitate the speed of diagnosis and implementation of emergency treatment.

\section{Supplementary Information}

The online version contains supplementary material available at https://doi. org/10.1186/s12903-021-01503-5.

Additional file 1. Patient data - 1007 patients with codifications.

Additional file 2. Initial statistical analysis.

\section{Acknowledgements}

All authors had equal contribution in preparing this manuscript.

\section{Authors' contributions}

Conceptualization, MJ and PAT; methodology, RIJ; software, AH; validation, MR, PAT; formal analysis, AH; investigation, MJ; resources, MJ, PAT; data curation, AH, RIJ; writing —original draft preparation, MJ; writing — review and editing, PAT; visualization, AH, RIJ; supervision, MR; project administration, MJ, MR; All authors read and approved the final manuscript.

\section{Funding}

None to declare.

\section{Availability of data materials}

The datasets generated during and analysed during the current study are not publicly available due to absence of a public storage online platform at our university, but are available from the corresponding author on reasonable request.

\section{Declarations}

\section{Ethics approval and consent to participate}

The study was approved by the Ethics Committee of Oradea University (No. 35698/19.02.2018) and was therefore performed in accordance with the ethical standards laid down in the 2008 Declaration of Helsinki and its later amendments. All patients included in the study signed an informed consent at the time of their admission to the clinical service, by which they gave their consent to participate in this study and to the use of their anonymized medical data for scientific purposes and publication. In the case of patients under the age of 18 , the informed consent was signed by the parent or their legal guardian.

\section{Consent for publication}

All patients included in the study signed an informed consent at the time of their admission to the clinical service, by which they gave their consent to the use of their anonymized medical data for scientific purposes and publication. In the case of patients under the age of 18 , the informed consent was signed by the parent or their legal guardian.

\section{Competing interesta}

None to declare.

\section{Author details}

1 Department of Oral and Maxillofacial Surgery, University of Oradea, Romania, Str. Piaț 1 Decembrie, no.10, 410073 Oradea, Romania. ${ }^{2}$ Research Center for Functional Genomics, Biomedicine and Translational Medicine, luliu Hatieganu" University of Medicine and Pharmacy, 400337 Cluj-Napoca, Romania. 3 Discipline of Oral Surgery, 2nd Department of Dental Medicine, "Victor Babeş" University of Medicine and Pharmacy, 2 Eftimie Murgu Sq., 300041 Timisoara, Romania.

Received: 22 December 2020 Accepted: 4 March 2021

Published online: 17 March 2021

\section{References}

1. Manodh P, Prabhu Shankar D, Pradeep D, Santhosh R, Murugan A. Incidence and patterns of maxillofacial trauma-a retrospective analysis of 3611 patients — an update. Oral Maxillofac Surg. 2016;20(4):377-83. https ://doi.org/10.1007/s10006-016-0576-z.

2. Boffano P, Roccia F, Zavattero E, et al. European Maxillofacial Trauma (EURMAT) project: a multicentre and prospective study. J Craniomaxillofac Surg. 2015:43(1):62-70. https://doi.org/10.1016/j.jcms.2014.10.011.

3. Tenț PA, Juncar RI, Juncar M. Clinical patterns and characteristics of midfacial fractures in Western Romanian population: a 10-year retrospective study. Med Oral Patol Oral Cir Bucal. 2019;24(6):e792-8. https://doi. org/10.4103/njcp.njcp_256_18.

4. Kostakis G, Stathopoulos P, Dais P, Gkinis G, Igoumenakis D, Mezitis M, et al. An epidemiologic analysis of 1,142 maxillofacial fractures and concomitant injuries. Oral Surg Oral Med Oral Pathol Oral Radiol. 2012;114(5 Suppl):S69-73. https://doi.org/10.1016/j.tripleo.2011.08.029.

5. Abdullah WA, Al-Mutairi K, Al-Ali Y, Al-Soghier A, Al-Shnwani A. Patterns and etiology of maxillofacial fractures in Riyadh City, Saudi Arabia. Saudi Dent J. 2012;25(1):33-8. https://doi.org/10.1016/j.sdentj.2012.10.004.

6. Batista AM, Ferreira Fde O, Marques LS, Ramos-Jorge ML, Ferreira MC. Risk factors associated with facial fractures. Braz Oral Res. 2012;26(2):119-25. https://doi.org/10.1590/s1806-83242012000200006.

7. Lee K. Global trends in maxillofacial fractures. Craniomaxillofac Trauma Reconstr. 2012;5:213-22. https://doi.org/10.1055/s-0032-1322535.

8. Mohammad S, Firas A, Sukaina R, Ameen K. Trends in the pattern of facial fractures in different countries of the world. Int J Morphol. 2012;30(2):745-56.

9. Bakardjiev A, Pechalova P. Maxillofacial fractures in Southern Bulgaria-a retrospective study of 1706 cases. J Craniomaxillofac Surg. 2007;35:14750. https://doi.org/10.1016/j.jcms.2007.01.005.

10. Chrcanovic BR. Factors influencing the incidence of maxillofacial fractures. Oral Maxillofac Surg. 2012;16(1):3-17. https://doi.org/10.1007/s1000 6-011-0280-y.

11. Kotecha S, Scanell J, Monaghan A, Williams RW. A four year retrospective study of 1062 patients presenting with maxillofacial emergencies at a specialist pediatric hospital. Br J of Oral Maxillofac Surg. 2007;46:293-6. https://doi.org/10.1016/j.bjoms.2007.11.011.

12. Zaleckas L, Pečiulienè V, Gendvilienè I, Pūrienè A, Rimkuvienè J. Prevalence and etiology of midfacial fractures: a study of 799 cases. Medicina (Kaunas). 2015;51(4):222-7. https://doi.org/10.1016/j.medici.2015.06.005.

13. Tent PA, Juncar RI, Lung T, Juncar M. Midfacial fractures: a retrospective etiological study over a 10-year period in Western Romanian population. Niger J Clin Pract. 2018;21:1570-5. https://doi.org/10.4103/njcp. njcp_256_18. 
14. de Lucena AL, da Silva Filho GF, de Almeida Pinto Sarmento TC, de Carvalho SH, Fonseca FR, de Santana Sarmento DJ. Epidemiological profile of facial fractures and their relationship with clinical-epidemiological variables. J Craniofac Surg. 2016;27(2):345-9. https://doi.org/10.1097/ scs.0000000000002381.

15. Choi SH, Gu JH, Kang DH. Analysis of traffic accident-related facial trauma. J Craniofac Surg. 2016;27(7):1682-5. https://doi.org/10.1097/ SCS.0000000000002916.

16. Lee CW, Foo QC, Wong LV, Leung YY. An overview of maxillofacial trauma in oral and maxillofacial tertiary trauma centre, Queen Elizabeth Hospital, Kota Kinabalu, Sabah. Craniomaxillofac Trauma Reconstr. 2017;10(1):16-21. https://doi.org/10.1055/s-0036-1584893.

17. Kar IB, Mahavoi BR. Retrospective analysis of 503 maxillo-facial trauma cases in Odisha during the period of Dec'04-Nov'09. J Maxillofac Oral Surg. 2012;11(2):177-81. https://doi.org/10.1007/s12663-011-0276-z.

18. Businger AP, Krebs J, Schaller B, Zimmermann H, Exadaktylos AK. Cranio-maxillofacial injuries in victims of interpersonal violence. Swiss Med Wkly. 2012;142:w13687. https://doi.org/10.4414/smw.2012.13687.

19. Mijiti A, Ling W, Tuerdi M, et al. Epidemiological analysis of maxillofacial fractures treated at a university hospital, Xinjiang, China: a 5-year retrospective study. J Craniomaxillofac Surg. 2013;42(3):227-33. https:// doi.org/10.1016/j.jcms.2013.05.005

20. Oginni FO, Oladejo T, Alake DP, Oguntoba JO, Adebayo OF. Facial bone fractures in Ile-Ife, Nigeria: an update on pattern of presentation and care. J Maxillofac Oral Surg. 2016;15(2):184-90. https://doi.org/10.1007/ s12663-015-0826-X.

21. Watt K, Purdie DM, Roche AM, McClure RJ. Risk of injury from acute alcohol consumption and the influence of confounders. Addiction. 2004;99(10):1262-2127. https://doi.org/10.111 1/j.1360-0443.2004.00823.x.

22. Aj S, Rm J, Sf M, Mc M. Facial fractures in a level I trauma centre: the importance of protective devices and alcohol abuse. Injury. 2011;32:353-6. https://doi.org/10.1016/s0020-1383(00)00245-x.

23. Zix JA, Schaller B, Lieger O, Saulacic N, Thorén H, lizuka T. Incidence, aetiology and pattern of mandibular fractures in central Switzerland. Swiss Med Wkly. 2011;141:w13207. https://doi.org/10.1016/s0020 $-1383(00) 00245-x$.

24. Halsey JN, Hoppe IC, Granick MS, Lee ES. A single-center review of radiologically diagnosed maxillofacial fractures: etiology and distribution. Craniomaxillofac Trauma Reconstr. 2017;10(1):44-7. https://doi. org/10.1055/s-0036-1597582.

25. Hyman DA, Saha S, Nayar HS, Doyle JF, Agarwal SK, Chaiet SR. Patterns of facial fractures and protective device use in motor vehicle collisions from 2007 to 2012. JAMA Facial Plast Surg. 2016;18(6):455-61. https:// doi.org/10.1001/jamafacial.2016.0733.

26. Roccia F, Savoini M, Ramieri G, Zavattero E. An analysis of 711 victims of interpersonal violence to the face, Turin, Italy. J Craniomaxillofac Surg. 2016;44(8):1025-8. https://doi.org/10.1016/j.jcms.2016.05.021.

27. Kamath RA, Bharani S, Hammannavar R, Ingle SP, Shah AG. Maxillofacial trauma in central Karnataka, India: an outcome of 95 cases in a regional trauma care centre. Craniomaxillofac Trauma Reconstr. 2012:5(4):197204. https://doi.org/10.1055/s-0032-1322536.

28. Blumer M, Kumalic S, Gander T, et al. Retrospective analysis of 471 surgically treated zygomaticomaxillary complex fractures. J Craniomaxillofac Surg. 2018;46(2):269-73. https://doi.org/10.1016/j.jcms.2017.11.010.

29. Helgeland E, Dahle IM, Leira JI, Loro LL. Maxillofacial fractures surgically managed at aalesund hospital between 2002 and 2009. Craniomaxillofac Trauma Reconstr. 2015;8(4):321-5. https://doi. org/10.1055/s-0035-1550062.

30. Jeon EG, Jung DY, Lee JS, Seol GJ, Choi SY, Paeng JY, Kim JW. Maxillofacial trauma trends at a tertiary care hospital: a retrospective study. Maxillofac Plast Reconstr Surg. 2014;36(6):253-8. https://doi.org/10.14402/ jkamprs.2014.36.6.253.

31. Hoppe IC, Kordahi AM, Paik AM, Lee ES, Granick MS. Examination of lifethreatening injuries in 431 pediatric facial fractures at a level 1 trauma center. J Craniofac Surg. 2014;25(5):1825-8. https://doi.org/10.1097/ SCS.0000000000001055.

32. Kraft A, Abermann E, Stigler R, et al. Craniomaxillofacial trauma: synopsis of 14,654 cases with 35,129 injuries in 15 years. Craniomaxillofac Trauma Reconstr. 2012;5(1):41-50. https://doi.org/10.1055/s-0031-1293520.
33. Batista AM, Marques LS, Batista AE, Falci SG, Ramos-Jorge ML. Urban-rural differences in oral and maxillofacial trauma. Braz Oral Res. 2012;26(2):1328. https://doi.org/10.1590/s1806-83242012000200008.

34. Smith H, Peek-Asa C, Nesheim D, Nish A, Normandin P, Sahr S. Etiology, diagnosis, and characteristics of facial fracture at a Midwestern level I trauma center. J Trauma Nurs. 2012;19(1):57-65. https://doi.org/10.1097/ JTN.0b013e31823a4c0e.

35. Esses DF, Costa FW, Sá CD, et al. Occupational group, educational level, marital status and deleterious habits among individuals with maxillofacial fractures: retrospective study. Med Oral Patol Oral Cir Bucal. 2018;23(1):e13-22. https://doi.org/10.4317/medoral.21969.

36. Oikarinen K, Schutz P, Thalib L, Sándor GK, Clokie C, Meisami T, et al. Differences in the etiology of mandibular fractures in Kuwait, Canada, and Finland. Dent Traumatol. 2004;20(5):241-5. https://doi.org/10.111 1/j.1600-9657.2004.00243.x.

37. Schneider D, Kämmerer PW, Schön G, Dinu C, Radloff S, Bschorer R. Etiology and injury patterns of maxillofacial fractures from the years 2010 to 2013 in Mecklenburg-Western Pomerania, Germany: a retrospective study of 409 patients. J Craniomaxillofac Surg. 2015;43(10):1948-51. https ://doi.org/10.1016/j.jcms.2015.06.028.

38. Brucoli M, Boffano P, Broccardo E, et al. The "European zygomatic fracture" research project: the epidemiological results from a multicenter European collaboration. J Craniomaxillofac Surg. 2019;47(4):616-21. https:// doi.org/10.1016/j.jcms.2019.01.026.

39. Buchanan EP, Hopper RA, Suver DW, Hayes AG, Gruss JS, Birgfeld CB. Zygomaticomaxillary complex fractures and their association with naso-orbito-ethmoid fractures: a 5-year review. Plast Reconstr Surg. 2012;130(6):1296-304. https://doi.org/10.1097/PRS.0b013e31826d1643.

40. Hallmer F, Anderud J, Sunzel B, Güner N, Andersson G. Jaw fractures diagnosed and treated at Malmö University Hospital: a comparison of three decades. Int J Oral Maxillofac Surg. 2010;39(5):446-51. https://doi. org/10.1016/j.ijom.2010.01.017.

41. Ali-Alsuliman D, Ibrahim EH, Braimah RO. Patterns of zygomatic complex bone fracture in Saudi Arabia. J Emerg Trauma Shock. 2018;11(3):170-4. https://doi.org/10.4103/JETS.JETS_12_18.

42. Obimakinde OS, Ogundipe KO, Rabiu TB, Okoje VN. Maxillofacial fractures in a budding teaching hospital: a study of pattern of presentation and care. Pan Afr Med J. 2017;26:218. https://doi.org/10.11604/ pamj.2017.26.218.11621.

43. Abosadegh MM, Rahman SA, Saddki N. Association of traumatic head injuries and maxillofacial fractures: a retrospective study. Dent Traumatol. 2017;33(5):369-74. https://doi.org/10.1111/edt.12349.

44. Motamedi MH, Dadgar E, Ebrahimi A, Shirani G, Haghighat A, Jamalpour MR. Pattern of maxillofacial fractures: a 5-year analysis of 8,818 patients. J Trauma Acute Care Surg. 2014;77(4):630-4. https://doi.org/10.1097/ ta.0000000000000369.

45. Gandhi S, Ranganathan LK, Solanki M, Mathew GC, Singh I, Bither S. Pattern of maxillofacial fractures at a tertiary hospital in northern India: a 4-year retrospective study of 718 patients. Dent Traumatol. 2011;27(4):257-62. https://doi.org/10.1111/j.1600-9657.2011.00996.x.

46. Gomes PP, Passeri LA, Barbosa JR, et al. A 5-year retrospective study of zygomatico-orbital complex and zygomatic arch fractures in Sao Paulo state, Brazil. J Oral Maxillofac Surg. 2006;64:63-7. https://doi.org/10.1016/j. joms.2005.09.012.

47. Emodi O, Wolff A, Srouji H, Bahouth H, Noy D, Abu El Naaj I, et al. Trend and demographic characteristics of maxillofacial fractures in level I trauma center. J Craniofac Surg. 2018;29:471-5. https://doi.org/10.1097/ SCS.0000000000004128.

48. $\mathrm{Vn} \mathrm{O}, \mathrm{To} \mathrm{A}, \mathrm{Oa} \mathrm{O}, \mathrm{O} \mathrm{D}$. Changing pattern of pediatric maxillofacial injuries at the Accident and Emergency Department of the University Teaching Hospital, Ibadan — a four-year experience. Prehosp Disaster Med. 2010;25(1):68-71. https://doi.org/10.1017/s1049023×0000769x.

49. Dongas P, Hall GM. Mandibular fracture patterns in Tasmania, Australia. Aust Dent J. 2002;47(2):131-7. https://doi.org/10.1111/j.1834-7819.2002. tb00316.x.

50. Al Ahmed HE, Jaber MA, Abu Fanas SH, Karas M. The pattern of maxillofacial fractures in Sharjah, United Arab Emirates: a review of 230 cases. Oral Surg Oral Med Oral Pathol Oral Radiol Endod. 2004;98(2):166-70. https:// doi.org/10.1016/j.tripleo.2004.01.020. 
51. Bataineh $A B$. Etiology and incidence of maxillofacial fractures in the north of Jordan. Oral Surg Oral Med Oral Pathol Oral Radiol Endod. 1998;86(1):31-5. https://doi.org/10.1016/s1079-2104(98)90146-9.

52. Natu SS, Pradhan H, Gupta H, et al. An epidemiological study on pattern and incidence of mandibular fractures. Plast Surg Int. 2012;2012:834364. https://doi.org/10.1155/2012/834364.

53. Atighechi S, Karimi G. Serial nasal bone reduction: a new approach to the management of nasal bone fracture. J Craniofac Surg. 2009;20(1):49-52. https://doi.org/10.1097/SCS.0b013e318190def5.
54. Li R, Zhang R, Li W, Pei F, He W. Analysis of 126 hospitalized elder maxillofacial trauma victims in central China. Med Oral Patol Oral Cir Bucal. 2015;20(4):e464-70. https://doi.org/10.4317/medoral.20551.

\section{Publisher's Note}

Springer Nature remains neutral with regard to jurisdictional claims in published maps and institutional affiliations.
Ready to submit your research? Choose BMC and benefit from:

- fast, convenient online submission

- thorough peer review by experienced researchers in your field

- rapid publication on acceptance

- support for research data, including large and complex data types

- gold Open Access which fosters wider collaboration and increased citations

- maximum visibility for your research: over $100 \mathrm{M}$ website views per year

At BMC, research is always in progress.

Learn more biomedcentral.com/submissions 